\title{
Sexual violence as a predictor of unintended pregnancy among married young women: evidence from the 2016 Nepal demographic and health survey
}

\author{
Kiran Acharya ${ }^{1 *+}$ (D) Yuba Raj Paudel ${ }^{2+}$ and Pramita Silwal ${ }^{3}$
}

\begin{abstract}
Background: Sexual violence in marital relationship is higher among women married at young age. Although sexual violence has been found to increase risk for unintended pregnancy, there is a limited published data from Nepal linking sexual violence with unintended pregnancy. The current study aimed to investigate association of partner sexual violence with unintended pregnancy among young married women who experienced child birth in last 5 years.

Methods: Using data from Nepal Demographic and Health Survey, we studied the prevalence of sexual violence and unintended pregnancy, and their association among 560 married women (weighted sample) of 15-24years who gave childbirth in last 5 years of the survey. We used multivariate logistic regression to analyse the association of sexual violence and other factors with unintended pregnancy. Analysis was conducted considering inverse probability weighting, clustering, and stratification to provide unbiased estimates of the population parameters.

Results: Nearly a quarter of women (22.7\%) reported to have experienced unintended pregnancy in the last 5 years of the survey and almost one in 10 women (9\%) reported to have ever experienced sexual violence from their husbands. Women who ever experienced sexual violence from their husbands were at 2.3 times higher odds to report an unintended pregnancy $(\mathrm{aOR}=2.3 ; 95 \% \mathrm{Cl}=1.1-4.8)$ compared to women who did not experience sexual violence from their husbands independent of important socio-demographic variables and ever use of contraception.

Conclusion: The strong association of sexual violence within marital relationship with unintended pregnancy among young women in Nepal necessitates the provision of comprehensive sexual and reproductive health services. Women need routine assessment, and referral to appropriate services for sexual violence to reduce unintended pregnancy and its consequences.
\end{abstract}

Keywords: Sexual violence, Unintended pregnancy, Young women, Nepal

\section{Background}

Sexual violence is widespread and deceptive problem that has serious physical, psychological, emotional and social consequences [1]. WHO defined sexual violence broadly as: "any sexual act, attempt to obtain a sexual act, unwanted sexual comments or advances, or acts to traffic, or otherwise directed, against a person's sexuality using coercion, by any person regardless of their

\footnotetext{
* Correspondence: acharya.kiran1@gmail.com

${ }^{\dagger}$ Kiran Acharya and Yuba Raj Paudel contributed equally to this work.

1 New ERA, Rudramati Marga, Kalopul, Kathmandu 44621, Nepal

Full list of author information is available at the end of the article
}

relationship to the victim, in any setting, including but not limited to home and work" [2]. Sexual violence against women does not only violate the rights of women and girls, but also limits their participation in society, and damages their health and well-being.

Previous studies have shown a relationship of domestic violence with abortion and unintended pregnancy [3-5]. A complex and multidirectional relationship is suggested to exist between induced abortion and violence [3]. A study from 4 Indian states (Bihar, Jharkhand, Maharastra, and Tamil Nadu) found that physical violence was associated with higher risk of induced abortion; and induced

(c) The Author(s). 2019 Open Access This article is distributed under the terms of the Creative Commons Attribution 4.0 International License (http://creativecommons.org/licenses/by/4.0/), which permits unrestricted use, distribution, and reproduction in any medium, provided you give appropriate credit to the original author(s) and the source, provide a link to the Creative Commons license, and indicate if changes were made. The Creative Commons Public Domain Dedication waiver (http://creativecommons.org/publicdomain/zero/1.0/) applies to the data made available in this article, unless otherwise stated. 
abortion was found to be leading to sexual and verbal violence [3]. A further analysis of DHS data found that women who experienced intimate partner violence (IPV) were more than twice the risk to abort their fetus in Azerbaijan and Moldova, whereas such women in Ukraine were nearly 5 times more likely to continue to unwanted live birth than women who did not ever experience physical and sexual violence from their husbands [5]. Similarly, secondary analysis of DHS data from Pakistan also found a higher likelihood of pregnancy loss(still birth, abortion) and unwanted pregnancy among women who experienced either emotional violence or physical violence or both [4]. Additionally, further analysis of DHS data from 10 countries found that women with history of intimate partner violence were $1.48-1.75$ times more likely to terminate pregnancy than women not experiencing IPV [6].

Nearly half of the women in South Asia face violence in their home [7]. Violence is an inevitable reality of women's lives since social and cultural norms that support violence have been institutionalized at all levels of their society: family, community, and state [7]. Violence against women is associated with underlying social, cultural, religious and gender norms and with the political instability [8]. One in two young married women reported to have experienced sexual violence within marriage in Nepal [9] and sexual violence is more common phenomenon than physical and emotional violence [10]. Adolescent and young women were more likely to have experienced sexual violence during early phase of their married life [11]. Research has documented negative consequences of sexual violence on physical and psychological health outcomes among Nepalese women [9].

Despite being a common phenomenon in Nepalese society, limited evidence is available on the association between sexual violence and unintended pregnancy in Nepal. It was estimated that 230,000-342,000 unintended pregnancies occurred in Nepal in 2011 [12]. Both the cross-sectional and prospective studies have revealed adverse consequences of unintended pregnancy to maternal and child health [12, 13]. Previous studies on correlates of unintended pregnancy in Nepal do not explore the association of sexual violence with pregnancy intendedness [14-16]. In this article we report on the prevalence of sexual violence from husbands in Nepal, and its association with unintended childbirth among currently married young women of 15-24 years who experienced child birth in last 5 years of the 2016 NDHS survey. We studied this age group because girls married at adolescent age were more likely to experience physical and sexual violence compared to those who were married at adult age $[11,17]$. The findings will help policy makers to make informed decision for reducing the burden of unintended pregnancy in Nepal.

\section{Methods}

We analyzed data from the 2016 Nepal Demographic and Health Survey (NDHS) which is a nationally representative survey. Women in the reproductive age group (15-49 years) from 11,040 households were interviewed in the 2016 NDHS survey. The survey involved the use of a three-stage stratified sampling technique. Stratification was achieved by separating each province into urban and rural areas.

\section{Sample selection}

From the sample households, women from selected households were chosen for administering domestic violence module. The unit of analysis for this study were women aged 15-24 ( $n=560$ weighted cases) who gave birth to at least one child in the last 5 years preceding the survey and who provided information on fertility preference in relation to the child after the child was born (Fig.1). The domestic violence module was randomly administered to only one woman in a household if there were more than one woman in a household.

\section{Definition of variables \\ Outcome variable}

Precise measurement of birth intentions was essential to define fertility behavior of women. Measurement of pregnancy intention in the DHS was based on a question to women for every live birth: 'When you were pregnant with [Name of the child] whether you wanted the pregnancy then, later or not at all?'. Women responding their last birth was 'wanted later' or 'not wanted at all' were characterized to have an unintended pregnancy and those who responded 'wanted birth then' were considered to have an intended pregnancy. Unintended pregnancy was coded ' 1 ' and intended pregnancy was coded ' 0 '. The terms 'unintended pregnancy' and 'unintended birth' are interchangeably used in this paper.

\section{Independent variables}

Eligible women were asked 3 questions: "Did you ever experience physical force by husbands to have sexual intercourse when you did not want to?", "Did your husband use physical force to perform any other sexual acts when you did not want to?"; and "Were you ever forced by your husband with threats or in any other way to perform sexual acts when you did not want to?". Ever experience of sexual violence (yes, no) was derived from the response to above 3 questions. If a women answered 'yes' to at least one of the above 3 questions, then it was considered as having experienced sexual violence. If a women answered 'No' to all 3 questions, then it was considered as no experience of sexual violence from husbands. Ever experience of sexual violence was coded ' 1 ' for 'yes' and ' 0 ' for 'no'. 


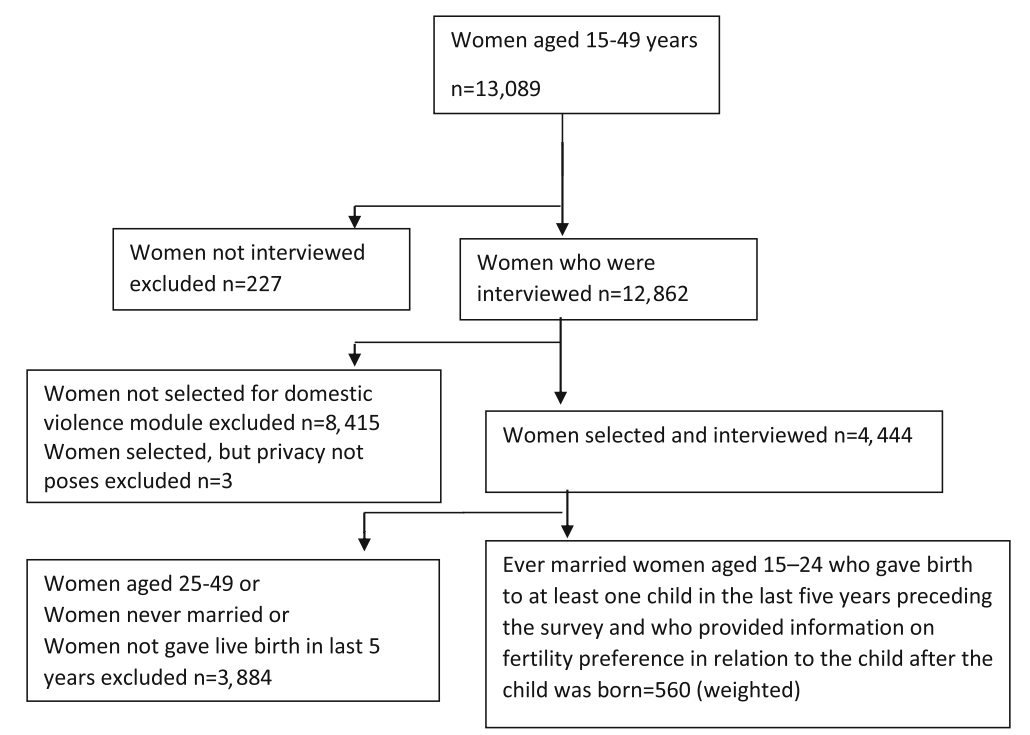

Fig. 1 Flow chart showing selection of study sample

Other covariates including socio-demographic characteristics, and reproductive health behavior of respondents and husband's characteristics used in the current analysis were drawn from the literature [18-21]. The analysis concentrated on three types of covariates related with violence: a) background/household ( $\mathrm{HH}$ ) characteristics; b) women's characteristics and c) husband's characteristics.

Background characteristics include: place of residence (urban/rural), province (province 1-7) ecological region: Mountain (northern mountain region of Nepal bordering China), Hill (mid hilly region) and Terai (plain region of Nepal), and wealth quintile of households. The wealth quintile in NDHS was calculated using principal component analysis based on household's ownership of selected assets, e.g. televisions and bicycles; materials used for housing construction; and types of water access and sanitation facilities. Using these proxy indicators, the households were classified into five quintiles: the poorest, poorer, middle, richer, and the richest. [22]. The quintiles were later grouped into three categories for the current analysis: poor (poorest and poorer), middle and rich (richer and richest) as has been suggested by Chakraborty et al. [23]. Women's characteristics include: age group of the women (15-19/20-24), caste of the women: Hill-Brahmin/Chettri (relatively advantaged), Terai caste (relatively advantaged living in southern plain region), Janajatis (indigenous groups) and Dalit/Others(disadvantaged populations), levels of education (no education/ primary/some secondary/SLC and above), current working status of women based on involvement in any work aside from own house work (yes/no), ever used contraception (yes/no), ideal family size as per her wish $(0-2 / 3+)$ and decision-making status (yes/no).The definition of decision making status is based on the definition given on sustainable development goals 2016-2030, i.e. the SDG Indicator 5.6.1: 'Proportion of women aged 15-49 years who make their own informed decisions regarding sexual relations, contraceptive use and reproductive health care'. Media exposure (frequency of reading newspaper or magazine, frequency of listening radio or frequency of watching television) were categorized into "Not at all", less than once a week and at least once a week. Husband related covariates included levels of education (no education/ primary/some secondary/SLC and above), occupation (not working/ agricultural/non-agricultural/manual labor) and alcohol consumption (yes/no).

\section{Statistical analysis}

Chi-square test was used to assess the association of sexual violence and other covariates with unintended pregnancy. Certain sub categories within categorical variables such as province (province 6 and 7); ecological region (mountain and hilly); husband education (None and primary) were merged due to few observations. Due to less number of cases in 'not working' category within 'husband's working status' was not shown in the tables of bivariate and multivariate analysis. Multi-collinearity of the independent variable was checked before running multivariate models.

Multivariate logistic regression analysis was used to derive adjusted effects of sexual violence on unintended pregnancy. Initially, ever experience of sexual violence and covariates related to women's fertility intention and decision-making (ever used contraception, ideal family size and her decision-making status), were included in the first model. Variables that showed significance in the 
first model $(p<0.05)$ were included in the second model which consisted socio-demographic characteristics of the women and their husbands. Odds ratios and $95 \%$ confidence intervals were presented in the results. Domestic violence weights from NDHS 2016 were applied during the analyses. We used the Svyset command to account for complex survey design and to provide unbiased estimates for odds ratio and their confidence intervals. The analyses were done using STATA version 15.0.

\section{Ethical considerations}

NDHS 2016 survey protocol was reviewed and approved by Nepal Health Research Council and the institutional review board of ICF Macro International. We used de-identified publicly available dataset from DHS website (www.dhsprogram.com) for this analysis. Therefore, no separate ethical approval was required for this analysis. In NDHS 2016, the interviewers pursued informed consent from the women before interviews. Privacy and confidentiality was ensured during interviews by trained female interviewers who received special training to administer the domestic violence module. Permission was obtained from Measure DHS to use the data for further analysis.

\section{Results}

\section{Prevalence of sexual violence and unintended last pregnancy}

Table 1 presents the prevalence of sexual violence and unintended pregnancy among women who had childbirth experience in the last 5 years of the survey. Nearly one in $10(9 \%)$ respondents reported to have ever experienced sexual violence from their husband. Nearly a quarter (23\%) of the respondents reported unintended pregnancy.

\section{Background characteristics of respondents}

Almost equal proportion of the respondents resided in the rural (50\%) and urban (50\%) areas. Most of the respondents were from province $2(26 \%)$ followed by province $5(19 \%)$ and province $1(15 \%)$. More than half

Table 1 Percentage of respondents ever married age 1524given birth in last 5 years who ever reported sexual violence by their current husband and unintended pregnancy

\begin{tabular}{lll}
\hline Characteristics & $n=560$ & $\%(95 \% \mathrm{Cl})$ \\
\hline Sexual violence & 51 & $9.0(6.3-12.8)$ \\
$\begin{array}{l}\text { Physically forced her to have sexual } \\
\text { intercourse with him when she did }\end{array}$ & 49 & $8.6(6.0-12.5)$ \\
not want to & & \\
$\begin{array}{l}\text { Physically forced her to perform any } \\
\text { Other sexual acts she did not want to }\end{array}$ & 17 & $3.1(1.78-5.2)$ \\
$\begin{array}{l}\text { Forced her with threats or in any other } \\
\text { way to perform sexual acts she did } \\
\text { not want to }\end{array}$ & 27 & $4.9(3.0-7.8)$ \\
\begin{tabular}{l} 
Unintended pregnancy (last birth) \\
\hline
\end{tabular} & 127 & $22.7(18.8-27.1)$ \\
\hline
\end{tabular}

of the respondents $(52 \%)$ were from Terai, $42 \%$ were from Hill and 6\% from Mountain. Nearly half $(48 \%)$ belonged to middle income households followed by poor (42\%). Caste-wise, more than one third (34\%) of the respondents were Janjatis (indigenous group) followed by Hill Brahmin/Chettri (25\%). Most of the respondents were in the age group 20-24 (82\%). Less than one fifth of the respondents had no education while almost half of them had either some secondary, school leaving certificate (SLC) or higher education. Nearly half (46\%) of respondents were currently working. Nearly two fifth (38\%) ever used contraception. Majority of respondents mentioned ideal family size to be less than 3 . Just over a quarter $(28 \%)$ of the respondents had media exposure at least once in a week while just over half (53\%) of them had media exposure less than once in a week. Nearly $70 \%$ of husbands had some secondary or SLC and higher education. Most of the husbands were engaged in manual labor and agriculture-related employment. About two fifth (41\%) of the respondents reported their husbands to be drinking alcohol (Table 2).

\section{Association between the independent characteristics and unintended pregnancy (last births)}

Table 2 shows that highest proportion of unintended last births were reported in province $3(36 \%)$, followed by province 2 (27\%) and province 6 and 7 (20\%). Proportion of unintended last births were higher among women who mentioned their ideal family size to be less than 3 (25\%) compared to those reporting it to be more than or equal to $3(9 \%)$. Nearly two fifth $(38 \%)$ of women who had experienced sexual violence from their husbands had experienced unintended last births. We found no difference in proportion of unintended last births by other independent characteristics.

\section{Effect of sexual violence on unintended pregnancy (live births)}

We created two multivariate logistic regression models to investigate adjusted effect of sexual violence on unintended pregnancy. In the first model, we included sexual violence, ever use of contraceptives, decision making status and perceived ideal family size. Variables that showed significance $(p<0.05)$ in the first model were included in the second model. In the second model (final model), variables selected from the first model and other socio-demographic covariates were included (Appendix).

Final model showed that women who experienced sexual violence were at 2.3 times higher risk to report an unintended birth $(\mathrm{OR}=2.3 ; 95 \% \mathrm{CI}=1.1-4.8)$ compared to those who did not experience sexual violence. Women reporting ideal family size to be more than equal to three were $80 \%$ less likely to have unintended births' than $<3$ family size (OR $=0.2$; $95 \% \mathrm{CI}=0.1-0.7$ ). 
Table 2 Association between selected characteristics and unintended pregnancy (last birth)

\begin{tabular}{llll}
\hline Independent Characteristics & Total, n (\%) & $\begin{array}{l}\text { Unintended last } \\
\text { births (\%) }\end{array}$ & p-value \\
\hline Total & 560 & 22.7
\end{tabular}

Geographical/Household characteristics

Place of residence

$\begin{array}{llll}\text { Urban } & 279(49.8) & 22.7 & \\ \text { Rural } & 281(50.2) & 22.7 & 0.981 \\ \text { Ecoregion } & & & \\ \text { Mountain/Hill } & 268(47.9) & 23.0 & \\ \text { Terai } & 291(52.1) & 22.4 & 0.892\end{array}$

Province

Province1

$85(15.2) \quad 17.1$

Province2

$148(26.4) \quad 27.0$

Province3

$82(14.7) \quad 36.3$

Province4

$55(9.7) \quad 19.4$

Province5

$107(19.1) \quad 14.4$

Province6 and 7

$83(14.9)$

20.2

Wealth index

Poor

$235(41.9) \quad 22.0$

Middle

Rich

Caste

$\begin{array}{lll}\text { Brahmin/Chettri-Hill } & 137(24.6) & 24.2 \\ \text { Terai caste } & 112(20.1) & 25.2 \\ \text { Janajatis } & 192(34.3) & 19.9 \\ \text { Dalit/Others } & 118(21.1) & 23.2\end{array}$

Women's Characteristics

Age group

$$
\text { 15-19 }
$$

20-24

Education

$\begin{array}{lll}\text { No education } & 98(17.6) & 15.4 \\ \text { Primary } & 128(22.9) & 25.2 \\ \text { Some secondary } & 200(35.7) & 24.1 \\ \text { SLC and above } & 133(23.8) & 23.5\end{array}$

Working status

$$
\text { No }
$$

Yes

$301(53.7) \quad 22.7$

$259(46.3) \quad 22.8$

Ever used contraception

$\begin{array}{lll}\text { No } & 345(61.7) & 22.5 \\ \text { Yes } & 214(38.3) & 23.1\end{array}$

Ideal family size ${ }^{a}$

$$
\begin{aligned}
& 0-2 \\
& 3+
\end{aligned}
$$

Decision making status ${ }^{\mathrm{b}}$

\begin{tabular}{|c|c|c|c|}
\hline Independent Characteristics & Total, n (\%) & $\begin{array}{l}\text { Unintended last } \\
\text { births (\%) }\end{array}$ & $\overline{p \text {-value }}$ \\
\hline No & $294(58.6)$ & 19.4 & \\
\hline Yes & $208(41.4)$ & 26.4 & 0.118 \\
\hline \multicolumn{4}{|l|}{ Media Exposure ${ }^{c}$} \\
\hline Not at all & $106(18.9)$ & 25.7 & \\
\hline At least once a week & $155(27.7)$ & 26.6 & \\
\hline Less than once a week & $299(53.4)$ & 19.6 & 0.353 \\
\hline \multicolumn{4}{|l|}{ Husband's characteristics } \\
\hline \multicolumn{4}{|l|}{ Education $^{d}$} \\
\hline No education/Primary & $170(30.8)$ & 20.7 & \\
\hline Some secondary & $280(50.7)$ & 24.7 & \\
\hline SLC and above & $102(18.5)$ & 20.4 & 0.633 \\
\hline \multicolumn{4}{|l|}{ Working Status ${ }^{\mathrm{e}}$} \\
\hline Did not work & $15(2.7)$ & 7.7 & \\
\hline Agricultural & $82(14.8)$ & 25.3 & \\
\hline Non-agricultural & $77(13.9)$ & 27.4 & \\
\hline Manuallabor & $379(68.6)$ & 21.7 & 0.501 \\
\hline \multicolumn{4}{|l|}{ Alcohol consumption } \\
\hline No & $333(59.5)$ & 20.9 & \\
\hline Yes & $227(40.4)$ & 25.3 & 0.304 \\
\hline \multicolumn{4}{|l|}{ Sexual violence } \\
\hline No & $509(91.0)$ & 21.2 & \\
\hline Yes & $51(9.0)$ & 38.1 & $0.010^{*}$ \\
\hline
\end{tabular}

Table 2 Association between selected characteristics and unintended pregnancy (last birth) (Continued)

${ }^{a}$ Three non-numeric responses were excluded from the analysis

$\mathrm{b}_{58}$ cases who did not responses any of the decision making questions were not shown in the table

${ }^{c}$ Media exposure includes the exposure of newspaper, radio and television

dEight don't know cases were excluded from the analysis

e $S$ even missing cases were excluded from the analysis

${ }^{*} p<0.05$

Women residing in province 3 were more likely to have unintended births than province $1(\mathrm{OR}=3.2 ; 95 \% \mathrm{CI}=$ $1.3-8.1)$. Women with primary $(\mathrm{OR}=2.2 ; 95 \% \mathrm{CI}=1.1-$ $4.4)$ and some secondary education $(\mathrm{OR}=2.3 ; 95 \% \mathrm{CI}=$ 1.0-5.2) were more likely to report unintended birth than women with no education (Table 3).

\section{Discussion}

This paper investigated the association of sexual violence with unintended pregnancy among Nepalese young women (15-24 years) who have had at least one child birth in the last 5 years of the NDHS survey. Nearly a quarter of women $(22.7 \%)$ who delivered in last 5 years mentioned to have experienced unintended pregnancy. The proportion of unintended pregnancy among young women (15-24 years) who gave birth in last 5 years was slightly lower than previous estimates for Nepalese women of reproductive age (15-49 years) (24.6\%) [14]. 
Table 3 Multivariate logistic regression analysis showing effect of sexual violence on unintended pregnancy in Nepal 2016

\begin{tabular}{|c|c|c|}
\hline \multirow[t]{2}{*}{ Characteristics } & Model 1 & Model 2 \\
\hline & OR $(95 \% \mathrm{Cl})$ & OR $(95 \% \mathrm{Cl})$ \\
\hline \multicolumn{3}{|c|}{ Ever experienced Sexual violence } \\
\hline No (Ref.) & 1 & 1 \\
\hline Yes & $2.9^{* *}(1.4-6.3)$ & $2.3^{*}(1.1-4.8)$ \\
\hline \multicolumn{3}{|l|}{ Ideal family size } \\
\hline 0-2 (Ref.) & 1 & 1 \\
\hline $3+$ & $0.3^{*}(0.1-0.8)$ & $0.2^{*}(0.1-0.7)$ \\
\hline \multicolumn{3}{|l|}{ Province } \\
\hline Province1(Ref.) & & 1 \\
\hline Province2 & & $2.3(0.8-6.2)$ \\
\hline Province3 & & $3.2^{*}(1.3-8.1)$ \\
\hline Province 4 & & $1.1(0.4-2.9)$ \\
\hline Province5 & & $0.7(0.3-1.8)$ \\
\hline Province 6 and 7 & & $1.1(0.5-2.3)$ \\
\hline \multicolumn{3}{|l|}{ Women's education } \\
\hline No education(Ref.) & & 1 \\
\hline Primary & & $2.2^{*}(1.1-4.4)$ \\
\hline Some secondary & & $2.3^{*}(1.0-5.2)$ \\
\hline SLC and above & & $2.4(0.9-6.5)$ \\
\hline
\end{tabular}

The differences in proportion of unintended pregnancy could be partly due to differences in age groups between two studies. Underestimation of burden of unintended pregnancy among young women in the current analysis is likely because we only included married women who had a live birth in last 5 years.

We found a strong association between ever experience of sexual violence from husbands and unintended pregnancy, aOR 2.3 (95\% CI 1.1-4.8) among women who gave childbirth in the last 5 years which was consistent with findings from previous studies [6, 24-27]. The strength of association found in our study is similar to a study from Burundi [25], but greater than reported in studies from Colombia [27] and Peru [24]. These differences in strength of association could be due to variations in statistical models and confounder adjustment. Current findings indicate that women experiencing sexual violence in Nepal have significantly higher chances of unintended pregnancy irrespective of their education, household-wealth, and other important socio-demographic factors. Analysis of DHS data showed that partner violence was associated with increased risk of unintended pregnancy in 8 out of 10 countries [6].

Current analysis revealed that nearly 1 in 10 women (9\%) had experienced sexual violence from their husbands ever in their life. The occurrence of sexual violence $(9 \%)$ from husbands/spouses over the lifetime in our sample is slightly higher than reported among Colombian youths aged 13-24 years of age (6\%) [27], and 20-24 years from Moldova (3\%) (6)but is lower than among youths aged 20-24 years from other low and middle income countries: Bolivia(14\%), Haiti(11\%), Kenya(15\%), Malawi(13\%) and Bangladesh (26\%) [6].

Unintended pregnancy among women who experienced sexual violence can occur through various pathways. First, male dominance in sexual decision making limits women's control over fertility, access to and use of contraceptives [27-29]. Second, unintended pregnancy can occur due to refusal to use condom by men; and women's fear of condom negotiation [29]. Third, women who experienced intimate partner violence may be more likely to experience pregnancy coercion or contraceptive sabotage increasing their risk of unintended pregnancy [30]. Fourth, chances of contraceptive failure [31], contraceptive discontinuation [32] and use of less reliable traditional methods [33] was reported to be higher among women experiencing intimate partner violence compared to those who did not experience violence.

We found that women who had primary and some secondary level education were more likely to experience unintended pregnancy than women who had no formal education. Women with above secondary level education showed the association in same direction but did not reach statistical significance. Current finding showing increased risk of unintended pregnancy among women with primary and some secondary education compared to women with no education is contradictory to earlier research among currently pregnant women from Nepal, which found no association between education and risk of unintended pregnancy [15]. The authors used a dichotomous variable (no education/illiterate and literate), while we used a variable with 4 levels of education. Differences in sample characteristics (age and pregnancy status) might explain this result or it might indicate a mediating role of sexual violence on the association of educational status with unintended pregnancy. Previous studies from Colombia and Bangladesh also found insignificant positive association between education and risk of unintended pregnancy [34]. Educated women may be more likely to reject traditional gender norms and may try to retaliate to their husband's sexual violence which may have led to further revenge from husbands in a male dominated society [10]. A study from Burundi showed that frequency of partner violence was more common among women with primary, secondary and tertiary education than among women with no education, probably due to reporting bias [25]. Educated women may be more likely to report any kind of sexual violence and unintended pregnancy than women with less/no education [6]. 
Whereas, non-educated women might normalize sexual violence in marital relationship than their educated counterparts, which might have led to under-reporting of sexual violence and unintended pregnancy [34]. Despite these findings, importance of women's education for positive health outcomes remains undisputed.

Although husband's educational level was not associated with unintended pregnancy, husbands' relative education to women may be another factor that played a role in sexual violence [10] and unintended pregnancy that needs further examination. Additionally, higher use of less effective traditional FP methods by educated women [35], might have led to higher rates of unintended pregnancy.

Women who expressed smaller ideal family size (less than 3 children), were more likely to experience unintended childbirth compared to women who wanted larger family size(more than 3). Adhikari et al. revealed similar findings from further analysis of NDHS 2011 data among pregnant women of 15-49 years from Nepal [15]. Since majority of Nepalese live in rural areas, women from rural areas might perceive greater benefit of having more children [15]. Further, women who wanted fewer children are more likely to be higher educated than women wanting more children [35]. Moreover, reproductive coercion and contraceptive sabotage by husbands might be more prevalent among women wanting fewer children than women wanting three or more children until desired sex composition is achieved since son preference was found to be equally prevalent among younger generations in Nepal [36].

Historically, sexual violence within marital relationship has remained an 'open secret' in Nepal [18]. Women who were illiterate, had lower autonomy to make decisions and who were raised in a family where violence was common were more likely to experience intimate partner violence [18]. Furthermore, lower autonomy and less inter-spousal communication were strongly associated with sexual violence among married young Nepalese women [10]. Social and cultural norms regarding women's behavior requires them to be submissive and loyal to their husbands. Given the association between sexual violence and unintended pregnancy, strong implementation of Domestic Violence (Offense and Punishment) Act 2009 [37], and efforts to improve inter-spousal communication, and women's autonomy needs to be in place to reduce the risk of unintended pregnancy in Nepal [10]. Research on dynamics of abuse and sexual violence in marital relationship is necessary to design prevention programs [38].

The current findings underscore the importance of multidimensional reproductive and sexual health services to married young women in Nepal for reducing unintended pregnancy and its consequences. Routine screening for sexual violence, and counseling or referral to appropriate services needs to be made available to all women. The family planning clinics and/or antenatal care sites can be used to provide information, counseling and services to reduce sexual violence and reproductive coercion [39]. Therefore, provision of screening and treatment for spousal violence within reproductive health care setting needs to be ensured [24]. Some promising violence prevention interventions (combining microfinance and gender equality training, improving couple communication and relationship skills, among others) need to be evaluated in Nepalese context for larger scale up [40].

Longer term reversible contraceptives reduce the risk of unintended pregnancy [41]. These may be more appropriate FP methods to women who are experiencing sexual violence but cannot live separately from abusive husbands. Similarly, female condoms and progesterone vaginal ring(PVR) can also enhance women's control over their fertility [42]. However, availability and use of female condoms and PVR is very limited in Nepal [35] and needs to be promoted in future.

We used data obtained from a nationally representative survey. We analyzed a sample of women of young adult age (15-24 years) because evidence suggests that young women are more likely to experience violence. The findings presented here need to be interpreted in the light of some limitations. It was difficult to determine temporal relationship between sexual violence and unintended pregnancy due to cross-sectional nature of the data used for analysis as some studies have demonstrated that unintended pregnancy/induced abortion can also lead to violence [3, 43]. Additionally, there is a high chance of under-reporting of sexual violence because of its sensitive nature. Further, unintended births may have been under-reported after a child is born because of the joy associated with having a child. Additionally, women who terminated their unintended pregnancy through abortion or who experienced still birth or child death were not included in the sample which could have influenced our strength of association between unintended pregnancy and sexual violence.

\section{Conclusion}

Sexual violence was strongly associated with unintended pregnancy among young women (15-24 years) who experienced child birth in last 5 years of the survey independent of ever use of contraceptives, women's education, and other important socio-demographic factors. Therefore, assessment for sexual violence in marital relationship and referral to appropriate services can help to identify women at risk of unintended pregnancy. Hence, along with the provision of range of contraceptives, $\mathrm{RH}$ service sites need to be strengthened to provide assessment, counseling or referral services for sexual violence to prevent unintended pregnancies. 
Table 4 Multivariate logistic regression analysis showing effect of sexual violence on unintended pregnancy in Nepal 2016

\begin{tabular}{|c|c|c|}
\hline \multirow[t]{2}{*}{ Characteristics } & Model 1 & Model 2 \\
\hline & OR $(95 \% \mathrm{Cl})$ & OR $(95 \% \mathrm{Cl})$ \\
\hline \multicolumn{3}{|c|}{ Ever experienced Sexual violence } \\
\hline No (Ref.) & 1 & 1 \\
\hline Yes & $2.9^{* *}(1.4-6.3)$ & $2.3^{*}(1.1-4.8)$ \\
\hline
\end{tabular}

Ever used contraception

$\begin{array}{ll}\text { No (Ref.) } & 1 \\ \text { Yes } & 0.9(0.6-1.5)\end{array}$

Decision making status

$\begin{array}{ll}\text { No(Ref.) } & 1 \\ \text { Yes } & 1.4(0.8-2.3)\end{array}$

Ideal family size

$\begin{array}{lll}0-2 \text { (Ref.) } & 1 & 1 \\ 3+ & 0.3^{*}(0.1-0.8) & 0.2^{*}(0.1-0.7)\end{array}$

Place of residence

Urban(Ref.)

Rural

Ecological region

Mountain/Hill(Ref.)

Terai

1

$1.0(0.6-1.6)$

1

$1.2(0.6-2.4)$

Province

Province1(Ref.)

Province2

Province3

Province 4

Province5

Province 6 and 7

Wealth index

$$
\text { Poor(Ref.) }
$$

Middle

Rich

Caste

Brahmin/Chettri-Hill(Ref.)

Terai caste

Janajatis

Dalit/Others

Women's age group

15-19(Ref.)

20-24

$0.8(0.4-1.4)$

Women's education

No education(Ref.)

Primary

Some secondary

SLC and above

$1.1(0.4-2.9)$

$0.7(0.3-1.8)$

$1.1(0.5-2.3)$

1

$0.9(0.5-1.6)$

$0.7(0.2-2.0)$

1

$0.9(0.4-2.5)$

$0.5(0.2-1.1)$

$1.0(0.5-2.1)$

1

1

$2.2^{*}(1.1-4.4)$

$2.3^{*}(1.0-5.2)$

$2.4(0.9-6.5)$
Table 4 Multivariate logistic regression analysis showing effect of sexual violence on unintended pregnancy in Nepal 2016 (Continued)

\begin{tabular}{|c|c|c|}
\hline \multirow[t]{2}{*}{ Characteristics } & Model 1 & Model 2 \\
\hline & OR (95\% Cl) & OR (95\% Cl) \\
\hline \multicolumn{3}{|l|}{ Women's working status } \\
\hline No(Ref.) & & 1 \\
\hline Yes & & $1.1(0.6-1.9)$ \\
\hline \multicolumn{3}{|l|}{ Media Exposure } \\
\hline Not at all(Ref.) & & 1 \\
\hline At least once a week & & $1.1(0.5-2.3)$ \\
\hline Less than once a week & & $0.7(0.3-1.4)$ \\
\hline \multicolumn{3}{|l|}{ Husband's education } \\
\hline No education(Ref.) & & 1 \\
\hline Primary & & $1.4(0.5-4.4)$ \\
\hline Some secondary & & $1.5(0.5-5.1)$ \\
\hline SLC and above & & $1.3(0.3-5.1)$ \\
\hline \multicolumn{3}{|l|}{ Husband's working Status } \\
\hline Did not work & & 1 \\
\hline Agricultural & & $4.3(0.5-36.5)$ \\
\hline Non-agricultural & & $3.7(0.5-28.3)$ \\
\hline Manual labor & & $3.5(0.5-25.9)$ \\
\hline \multicolumn{3}{|c|}{ Alcohol consumption by husband } \\
\hline No(Ref.) & & 1 \\
\hline Yes & & $1.3(0.8-2.3)$ \\
\hline
\end{tabular}

Ref. Reference

${ }^{*} p<0.01, * 0<0.05$

\section{Abbreviations}

aOR: Adjusted odds ratio; Cl: Confidence interval; DHS: Demographic and Health Survey; FP: Family planning; HH: Household; NDHS: Nepal Demographic and Health Survey; OR: Odds ratio; $p$-value: Probability value; PVR: Progesterone vaginal ring; SDG: Sustainable development goal; SLC: School leaving certificate; WHO: World Health Organization

\section{Acknowledgements}

The authors would like to acknowledge the MEASURE DHS program for providing the NDHS datasets.

Funding

No funding was granted to the authors but the article processing charge has been granted by the waiver/Biomed Central.

Availability of data and materials

Data was available through MEASURE DHS program (www.dhsprogram.com).

\section{Authors' contributions}

Conceptualization (KA and YRP), Data Analysis (KA), Methodology (KA and YRP), Supervision (KA and YRP), Validation (KA and YRP), Writing-original draft, review and editing (KA, YRP and PS), read and approved the final version of the manuscript (KA, YRP and PS)

\section{Ethics approval and consent to participate}

DHS surveys in Nepal were reviewed and approved by the Institutional Review Board of Nepal Health Research Council, Nepal; data were publicly 
available and did not include individual identities and thus did not require ethics approval.

\section{Consent for publication \\ Not Applicable.}

\section{Competing interests}

The authors declare that there are no conflict interests regarding the publication of this paper. The views and opinions expressed in this article are those of the authors and do not necessarily reflect the official policy or position of the organizations authors are affiliated with.

\section{Publisher's Note}

Springer Nature remains neutral with regard to jurisdictional claims in published maps and institutional affiliations.

\section{Author details}

${ }^{1}$ New ERA, Rudramati Marga, Kalopul, Kathmandu 44621, Nepal. ${ }^{2}$ School of Public Health, University of Alberta, Edmonton, Canada. ${ }^{3}$ Nepal Red Cross Society, Kalimati, Kathmandu 44600, Nepal.

\section{Received: 22 November 2018 Accepted: 14 May 2019 Published online: 07 June 2019}

\section{References}

1. García-Moreno C, Jansen HA, Ellsberg M, Heise L, Watts C. WHO multicountry study on women's health and domestic violence against women: initial results on prevalence, health outcomes and women's responses: World Health Organization; 2005, [https://www.who.int/reproductivehealth/ publications/violence/24159358X/en/. Accessed 7 Jan 2019].

2. Cardia N. World report on violence and health. Bull World Health Organ. 2002;80(11):915 [https://apps.who.int/iris/handle/10665/268669. Accessed 10 Feb 2019].

3. Stephenson R, Jadhav A, Winter A, Hindin M. Domestic violence and abortion among rural women in four Indian states. Violence against women. 2016;22(13):1642-58.

4. Zakar R, Nasrullah M, Zakar MZ, Ali H. The association of intimate partner violence with unintended pregnancy and pregnancy loss in Pakistan. Int J Gynecol Obstet. 2016;133(1):26-31.

5. Ismayilova L. Intimate partner violence and unintended pregnancy in Azerbaijan Moldova and Ukraine, DHS Working Papers No. 79. Calverton Maryland, USA,2010.

6. Hindin MJ, Kishor S, Ansara DL. Intimate partner violence among couples in 10 DHS countries: predictors and health outcomes; 2008.

7. Mehta M. Towards ending violence against women in South Asia: Oxfam International; 2004

8. Nanda P, Gautam MA, Verma R, Hong KT, Linh MTG, Puri M, et al. Study on gender, masculinity and son preference in Nepal and Vietnam. New Delhi: International Center for Research on Women; 2012

9. Puri M, Tamang J, Shah I. Suffering in silence: consequences of sexual violence within marriage among young women in Nepal. BMC Public Health. 2011;11(1):29.

10. Lamichhane P, Puri M, Tamang J, Dulal B. Women's status and violence against young married women in rural Nepal. BMC Womens Health. 2011;11(1):19.

11. García-Moreno C, Pallitto C, Devries K, Stöckl H, Watts C, Abrahams N. Global and regional estimates of violence against women: prevalence and health effects of intimate partner violence and non-partner sexual violence: World Health Organization; 2013.

12. Singh A, Singh A, Thapa S. Adverse consequences of unintended pregnancy for maternal and child health in Nepal. Asia Pac J Public Health. 2015:27(2):NP1481-NP91.

13. Singh A, Singh A, Mahapatra B. The consequences of unintended pregnancy for maternal and child health in rural India: evidence from prospective data. Matern Child Health J. 2013:17(3):493-500.

14. Acharya P, Gautam R, Aro AR. Factors influencing mistimed and unwanted pregnancies among Nepali women. J Biosoc Sci. 2016:48(2):249-66.

15. Adhikari R, Soonthorndhada K, Prasartkul P. Correlates of unintended pregnancy among currently pregnant married women in Nepal. BMC Int Health Hum Rights. 2009;9(1):17.
16. Bastola K, Neupane S, Hadkhale K, Kinnunen TI. Unintended pregnancy among married pregnant women in Nepal. J Womens Health Issues Care. 2015:4:4.

17. Raj A, Saggurti N, Lawrence D, Balaiah D, Silverman JG. Association between adolescent marriage and marital violence among young adult women in India. Int J Gynecol Obstet. 2010;110(1):35-9.

18. Atteraya MS, Gnawali S, Song $\mathbb{H}$. Factors associated with intimate partner violence against married women in Nepal. J Interpers Violence. 2015;30(7):1226-46.

19. Speizer IS, Pearson E. Association between early marriage and intimate partner violence in India: a focus on youth from Bihar and Rajasthan. J Interpers Violence. 2011;26(10):1963-81.

20. Santhya K, Haberland N, Ram F, Sinha R, Mohanty S. Consent and coercion: examining unwanted sex among married young women in India. Int Fam Plan Perspect. 2007:33:124-32.

21. Anand E, Unisa S, Singh J. Intimate partner violence and unintended pregnancy among adolescent and young adult married women in south asia. J Biosoc Sci. 2017;49(2):206-21.

22. Rutstein SO, Johnson K. The DHS wealth index. DHS comparative reports no. 6. Calverton: ORC Macro. 2004.

23. Chakraborty NM, Fry K, Behl R, Longfield K. Simplified asset indices to measure wealth and equity in health programs: a reliability and validity analysis using survey data from 16 countries. Glob Health Sci Pract. 2016:4(1):141-54

24. Cripe SM, Sanchez SE, Perales MT, Lam N, Garcia P, Williams MA. Association of intimate partner physical and sexual violence with unintended pregnancy among pregnant women in Peru. Int J Gynecol Obstet. 2008;100(2):104-8.

25. Elouard Y, Weiss C, Martin-Hilber A, Merten S. Sexual violence as a risk factor for family planning-related outcomes among young Burundian women. Int J Public Health. 2018;63(1):13-22.

26. Pallitto CC, O'Campo $P$. The relationship between intimate partner violence and unintended pregnancy: analysis of a national sample from Colombia. Int Fam Plan Perspect. 2004:30:165-73.

27. Gomez AM. Sexual violence as a predictor of unintended pregnancy, contraceptive use, and unmet need among female youth in Colombia. Women's Health. 2011;20(9):1349-56.

28. McFarlane J, Malecha A, Watson K, Gist J, Batten E, Hall I, et al. Intimate partner sexual assault against women: frequency, health consequences, and treatment outcomes. Obstet Gynecol. 2005;105(1):99-108.

29. Silverman JG, McCauley HL, Decker MR, Miller E, Reed E, Raj A. Coercive forms of sexual risk and associated violence perpetrated by male partners of female adolescents. Perspect Sex Reprod Health. 2011:43(1):60-5.

30. Miller E, Decker MR, McCauley HL, Tancredi DJ, Levenson RR, Waldman J, et al. Pregnancy coercion, intimate partner violence and unintended pregnancy. Contraception. 2010;81(4):316-22.

31. Raj A, McDougal L. Associations of intimate partner violence with unintended pregnancy and pre-pregnancy contraceptive use in South Asia. Contraception. 2015;91(6):456-63.

32. Allsworth JE, Secura M. G, Zhao Q, madden T, Peipert JF. The impact of emotional, physical, and sexual abuse on contraceptive method selection and discontinuation. Am J Public Health. 2013;103(10):1857-64.

33. Taft AJ, Powell RL, Watson LF. The impact of violence against women on reproductive health and child mortality in Timor-Leste. Aust N Z J Public Health. 2015;39(2):177-81.

34. Raihana S, Shaheen R, Rahman MS. Influence of intimate partners' violence on unintended pregnancy in Bangladesh. Int J Psychol Behav Sci. 2012;2(5):159-66.

35. Ministry of Health and Population. (MoHP) Nepal, new ERA, and ICF international Inc. Nepal demographic and health survey 2016. Kathmandu: Ministry of Health and Population; 2017.

36. Paudel $Y R$, Acharya K. Fertility limiting intention and contraceptive use among currently married men in Nepal: evidence from Nepal demographic and health survey 2016. Biomed Res Int. 2018;2018:5970705.

37. Domestic Violence (Offence and Punishment) Act, 2009. 2009. http://www. lawcommission.gov.np/en/archives/13736. Accessed 7 Jan 2019.

38. Wood K, Maforah F, Jewkes R. "He forced me to love him": putting violence on adolescent sexual health agendas. Soc Sci Med. 1998;47(2):233-42.

39. Miller E, Decker MR, McCauley HL, Tancredi DJ, Levenson RR, Waldman J, et al. A family planning clinic partner violence intervention to reduce risk associated with reproductive coercion. Contraception. 2011;83(3):274-80. 
40. World Health Organization. Violence against women: intimate partner and sexual violence against women: intimate partner and sexual violence have serious short-and long-term physical, mental and sexual and reproductive health problems for survivors: fact sheet. Geneva: World Health Organization; 2014. http://www.who.int/iris/handle/10665/112325.

41. Modi MN, Heitmann RJ, Armstrong AY. Unintended pregnancy and the role of long-acting reversible contraception. Expert Rev Obstet Gynecol. 2013;8(6):549-58.

42. RamaRao S, Obare F, Ishaku S, Mané B, Clark H, Liambila W, et al. Do women find the progesterone vaginal ring acceptable? Findings from Kenya, Nigeria, and Senegal. Stud Fam Plan. 2018;49(1):71-86.

43. Amaro $H$, Fried $L E$, Cabral $H$, Zuckerman B. Violence during pregnancy and substance use. Am J Public Health. 1990;80(5):575-9.

Ready to submit your research? Choose BMC and benefit from:

- fast, convenient online submission

- thorough peer review by experienced researchers in your field

- rapid publication on acceptance

- support for research data, including large and complex data types

- gold Open Access which fosters wider collaboration and increased citations

- maximum visibility for your research: over $100 \mathrm{M}$ website views per year

At $\mathrm{BMC}$, research is always in progress.

Learn more biomedcentral.com/submissions 